\title{
Gust Load Alleviation Control for Very Flexible Aircraft
}

\author{
Matthew J. Dillsaver ${ }^{1}$, Carlos E.S. Cesnik ${ }^{2}$, Ilya V. Kolmanovsky ${ }^{3}$ \\ The University of Michigan, Ann Arbor, Michigan, 48109, USA
}

\begin{abstract}
This paper focuses on the development of a wind gust load alleviation control system for implementation in very flexible aircraft. The gust load alleviation system is designed using Linear Quadratic Gaussian (LQG) control techniques, and it is based on a nonlinear model of the coupled rigid-body and elastic modes of a very flexible aircraft. The nonlinear model contains the dynamics of the aircraft body reference frame, elastic strains, strain rates and unsteady aerodynamic flow states. The nonlinear model is linearized at a typical operating point corresponding to steady straight level flight conditions. Using model order reduction techniques, a lower order control-oriented model for the longitudinal dynamics of the very flexible aircraft is obtained. Assuming that the gust field is stochastic, the aircraft model is augmented with the disturbance model that matches the experimentally observed von Karman and Dryden power spectral density characteristics. A LQG controller is then designed to reduce the structural deflections, as the aircraft responds to the gust. Additionally, a command tracking control system is presented for longitudinal flight, which tracks a pitch angle command in the presence of a gust disturbance. It is demonstrated that the hard limits on the structural deflections while responding to the pitch angle command can be enforced using reference governor techniques.
\end{abstract}

\section{Introduction}

$\mathrm{V}$ ERY flexible aircraft (VFA) technology is rapidly becoming a focus for aircraft designers, particularly for Unmanned Aerial Vehicles. High altitude, long endurance (HALE) is a class of VFA aircraft currently garnering increased attention due to their potential civilian and military uses. These include environmental sensing and cellular telephone relay on the civilian side ${ }^{1}$ and Intelligence, Surveillance, and Reconnaissance missions and communication relay for the military applications. ${ }^{2}$

The mission requirements for HALE aircraft lead them to be designed with certain attributes. First, these aircraft tend to have high aspect ratio wings, allowing high lift-to-drag ratios, thereby maximizing aerodynamic efficiency. Moreover, due to the long endurance requirements, the structural weight fraction is as small as possible. These features lead the aircraft to be very flexible, with large wing deformations possible. In fact, wingtip deflections as high as $43 \%$ of the half span have been noted. ${ }^{3}$ Another important aspect encountered in VFA is the range overlap between the lowest elastic mode frequencies with the rigid-body flight dynamic frequencies.

There have been many studies in the recent literature addressing different aspects of VFA. Among them, Patil, Hodges, and Cesnik ${ }^{4}$ studied the aeroelasticity and flight dynamics of VFA and show that significant changes in the aircraft characteristics can be caused by large deflections of flexible wings. The actual shape of VFA wings can vary greatly during different flight conditions. As pointed out by Su and Cesnik, ${ }^{5}$ the aeroelastic analysis must be based on the actual trimmed shape of the aircraft. Additionally, a linear aeroelastic analysis based on undeformed geometry could lead to errors in highly flexible wings. Palacios and Cesnik ${ }^{6}$ compared displacement-based, strainbased and geometrically nonlinear beam models and found that a combination of the methods may provide the best solution. Specifically, that using a displacement-based method for the fuselage and tail and a strain-based or geometrically nonlinear beam model for the flexible wing could provide the best solution. Palacios, Murua and

\footnotetext{
${ }^{1}$ Captain, US Air Force, Ph.D. Pre-Candidate (dills@umich.edu), Dept of Aerospace Engineering, Member, AIAA.

2 Professor (cesnik@umich.edu), Dept of Aerospace Engineering, Associate Fellow, AIAA.

${ }^{3}$ Professor (ilya@umich.edu), Dept of Aerospace Engineering, Member, AIAA.
} 
$\operatorname{Cook}^{7}$ evaluated multiple two and three-dimensional structural and aerodynamic models for use with nonlinear flight dynamics of VFA aircraft. They found that two-dimensional methods suffice for small deformations, but that a three-dimensional vortex-lattice method was needed for large amplitude deformations. A state-space form of the discrete intrinsic beam equations for use in flight dynamic analysis is also presented. Zhou and $\operatorname{Ren}^{8}$ presented a method for studying the coupled dynamic behavior of a maneuvering flexible aircraft by modeling the aircraft as a feedback-controlled multi-body system. This time-domain method can be used for conceptual aircraft design.

The same attributes that allow HALE aircraft to operate well in their intended environment also leave them susceptible to external disturbances, such as gust. This was made evident with the Aerovironment Helios mishap in June 2003. The aircraft encountered turbulence in flight, causing an unexpected, high dihedral flight condition. As a result, the aircraft entered an unstable, diverging pitch oscillation with airspeed excursions doubling with every oscillation. The aircraft's design airspeed was eventually exceeded, causing it to break apart and fall into the Pacific Ocean. ${ }^{3}$ The nonlinearities and coupling between aerodynamics and structural modes lead to difficulties in the modeling, simulation and control of HALE aircraft. In fact, one of the recommendations from the Helios accident report was to "develop more advanced, multi-disciplinary (structures, aeroelastic, aerodynamics, atmospheric, materials, propulsion, controls, etc.) time-domain analysis methods appropriate to highly-flexible, morphing vehicles." 9

Gust load alleviation (GLA) control systems attempt to attenuate aircraft loads caused by the aircraft flying through turbulence. According to Mclean, ${ }^{10}$ the use of active control while the aircraft is in turbulence will lead to reduced airframe loads, reduced acceleration at particular aircraft stations, and improved flying qualities. Several methods have been shown to have a positive effect on reducing gust loads for conventional aircraft. Botez, Boustani, and Vayani ${ }^{11}$ use Linear Quadratic Gaussian (LQG) control to reduce vertical accelerations by $99 \%$. Aouf, Boulet, and Botez ${ }^{12}$ consider the gust as a bounded, deterministic finite-energy signal and then applied $\mathrm{H}_{2}$, weighted $\mathrm{H}_{2}$, and $\mathrm{H}_{\infty}$ techniques. They showed that the weighted $\mathrm{H}_{2}$ and $\mathrm{H}_{\infty}$ designs reduced vertical acceleration dramatically when compared to $\mathrm{H}_{2}$ control. Rui, Xiaoping, and Zhou ${ }^{13}$ use static output feedback to reduce the wingtip deflections of a flexible, solar powered UAV by $33 \%$.

Most current work in GLA control applies various modern control techniques to reducing aircraft loads by minimizing vertical acceleration. VFA aircraft exhibit large structural deflection which could lead to significant vertical acceleration differences across the span. Reducing the wingtip deflections is another current method for GLA control. While this may provide good results under most flight conditions, it could have difficulties if the gust causes a VFA to enter an unusual span-wise shape. This paper presents a method for reducing the gust loads by controlling the span-wise shape of the wing. The wing curvature is measured at multiple points on the wing so that many different wing shapes can be controlled. The addition of a reference governor also allows the control system to apply hard limits on the wing curvature at different points along the span.

\section{Theoretical Formulations}

\section{A. Gust Modeling}

There are two main approaches for modeling disturbances caused by gust: continuous and stochastic. The Federal Aviation Regulation (FAR) Part $23^{14}$ uses a continuous model given by:

$$
U=\frac{U_{d e}}{2}\left[1-\cos \left(\frac{2 \pi s}{25 C}\right)\right]
$$

where $U$ is the gust velocity in $\mathrm{ft} / \mathrm{sec}, s$ is the distance penetrated into the gust, $C$ is the mean geometric chord and $U_{d e}$ is the derived gust velocity which varies from 38 to $66 \mathrm{ft} / \mathrm{sec}$ depending on the design altitude, aircraft category, and air roghness. ${ }^{14}$ Another commonly used approach is a stochastic model. The gust is modeled as a stationary, random, Gaussian process. There are two commonly used models, both based on power spectral densities: the Dryden model and the von Karman model. The von Karman model has been shown to provide a better match to experimental data. ${ }^{15}$ The PSD for the von Karman gust model is given by:

$$
\Phi(\Omega)=\sigma_{w}^{2} \frac{L}{\pi} \frac{1+\frac{8}{3}(1.339 L \Omega)^{2}}{\left[1+(1.339 L \Omega)^{2}\right]^{11 / 16}}
$$


where $\Omega$ is the spatial frequency, $\sigma_{w}$ is the root mean square gust velocity (ft/sec), $L$ is the scale of turbulence (commonly assumed to be $2500 \mathrm{ft}$ ). In control design, disturbances are modeled using a coloring filter. The transfer function, G(s), of such filter is designed so that the input, $u$, is Gaussian white noise and the output, y, has the desired power spectral density. ${ }^{16}$ In this case, the output has a power spectral density of the von Karman gust model. Hoblit constructed an approximate filter for the von Karman mode ${ }^{11}$ which is given by:

$$
G(s)=\frac{\sigma_{w} \sqrt{\tau}}{\pi} \frac{(1+2.187 \tau s)(1+0.1833 \tau s)(1+0.021 \tau s)}{(1+1.339 \tau s)(1+1.118 \tau s)(1+0.1277 \tau s)(1+0.0146 \tau s)}
$$

where $\tau=\frac{L}{V}$. This is an excellent approximation for values of $L \Omega$ ranging from 0 to 200 . Assuming $L=2500 \mathrm{ft}$, this corresponds to a $\Omega / 2 \pi$ range of 0 to 0.013 cycles/ft. ${ }^{15}$ Hoblit also showed that the Dryden power spectral density shape can be matched exactly by the following filter:

$$
G(s)=\sigma_{w} \sqrt{\frac{\tau}{\pi}} \frac{1+\sqrt{3} \tau s}{(1+\tau s)^{2}}
$$

Additionally, the span-wise distribution of the gust profile must be determined. Dietrich ${ }^{17}$ stated that when the wingspan is less than approximately $10 \%$ of the turbulence scale, the distribution across the span can be considered constant. If the turbulence scale is taken to be $2500 \mathrm{ft}$ (762 m), aircraft with wingspan up to $250 \mathrm{ft}$ can be considered under the constant span-wise gust distribution assumption. Non-uniform span-wise gust distribution will be considered in future work.

\section{B. Aircraft Modeling}

The starting point for the modeling is the University of Michigan's Nonlinear Aeroelastic Simulation Toolbox (UM/NAST). UM/NAST uses a strain-based elastic formulation and is capable of simulating rigid body, linearized and nonlinear aircraft dynamics. ${ }^{18}$ The unsteady aerodynamics are modeled using an inflow state method developed by Peters and Johnson. ${ }^{19}$

A strain-based formulation of the nonlinear equations of motion for flexible aircraft based upon the principle of virtual work used in this study is given by: ${ }^{20}$

$$
\begin{gathered}
M_{F F} \ddot{\varepsilon}=-M_{F B} \dot{\beta}-C_{F F} \dot{\varepsilon}-C_{F B} \beta-K_{F F} \varepsilon+R_{F} \\
M_{B B} \dot{\beta}=-M_{B F} \ddot{\varepsilon}-C_{B B} \beta-C_{B F} \dot{\varepsilon}+R_{B} \\
\dot{\zeta}=-\frac{1}{2} \Omega_{\zeta} \zeta \\
\dot{p_{b}}=\left[\begin{array}{cc}
B G & 0
\end{array}\right] \beta \\
\dot{\lambda}=F_{1} \ddot{q}+F_{2} \dot{q}+F_{3} \lambda
\end{gathered}
$$

where $M$ is the generalized mass matrix, $C$ is the structural damping matrix, $K$ is the stiffness matrix, $R$ represents the generalized forces, the subscript $F$ denotes flexible terms, the subscript $B$ denotes terms in the body-fixed coordinate system, $\varepsilon$ is the strain vector containing the four strain elements (extensional strain, twist of the beam reference line, and bending about the $y$ and $z$ axis), $\beta$ is the rigid body velocity vector containing three translational and three rotational velocities, $\zeta$ represents the four quaternions, $p_{b}$ is a position vector for the body, $C^{B G}$ is a translation matrix for the body fixed coordinate system to the inertial system. The last equation calculates the unsteady aerodynamic forces and moments. 
Using a method based on Cesnik and $\mathrm{Su}^{21}$ the equations are linearized about an aircraft trim condition. This linearization gives rise to a differential equation of the form:

$$
Q_{1} \dot{x}=Q_{2} x+Q_{3} u+Q_{4} w
$$

where the state vector, $x$, is given by $\left[\varepsilon, \dot{\varepsilon}, \beta, \zeta, p_{b}, \lambda\right]^{T}$. The normal linearized matrices (see Section II-C) are then formed by taking $A=Q_{1}^{-1} Q_{2}, B=Q_{1}^{-1} Q_{3}, B_{w}=Q_{1}^{-1} Q_{3}$.

\section{Control Design}

Before starting any control design, the number of states representing the plant should be adequate. If the number of states in the linearized model is too large, this complicates the control development. Consequently, a model order reduction needs to be performed. The balanced truncation approach will be used in this study. The balanced truncation is based on the Observability and Controllability Grammians given by $P$ and $Q$, respectively, using:

$$
\begin{aligned}
& P=\int_{0}^{\infty} e^{A \tau} B B^{T} e^{A^{T} \tau} d \tau \\
& Q=\int_{0}^{\infty} e^{A^{T} \tau} C^{T} C e^{A \tau} d \tau
\end{aligned}
$$

where $A, B$, and $C$ are the matrices in the linearized model given by:

$$
\begin{aligned}
& \dot{x}=A x+B u \\
& y=C x+D u
\end{aligned}
$$

The Grammians can be computed as solutions to the following Lyapunov equations: ${ }^{22}$

$$
\begin{aligned}
& A P+P A^{T}+B B^{T}=0 \\
& A^{T} Q+Q A+C^{T} C=0
\end{aligned}
$$

A balanced realization of the system linear model is an asymptotically stable, minimal realization for which Grammians are equal $(P=Q)$ diagonal matrices.

The Hankel singular values are calculated as $\sigma_{i}=\sqrt{\lambda_{i}(P Q)}$, where $\lambda_{\mathrm{i}}$ 's denote the eigenvalues of the system. The Hankel singular values quantify the contribution each state has to the input-output response of the overall system. The states corresponding to the lowest Hankel singular values are then simply discarded, giving rise to a reduced order model with similar response characteristics to the original model.

A widely accepted method of control design when dealing with systems affected by Gaussian noise/disturbances is through the use of a Linear Quadratic Gaussian (LQG) controller. The LQG allows one to trade off regulation performance and control effort, while taking into account process and measurement noise. ${ }^{23}$ The LQG is essentially the combination of a Kalman filter and a Linear Quadratic Regulator (LQR). Due to the separation principle, the Kalman filter and LQR can be designed independently. ${ }^{23}$ A block diagram of an LQG controller is shown in Fig. 1, where $\mathrm{w}$ is the disturbance signal, $\mathrm{y}$ is the vector of the measured outputs, $\mathrm{u}$ is the control signal generated by the $\mathrm{LQR}$, and $\hat{x}$ is the state estimate produced by the Kalman filter. 


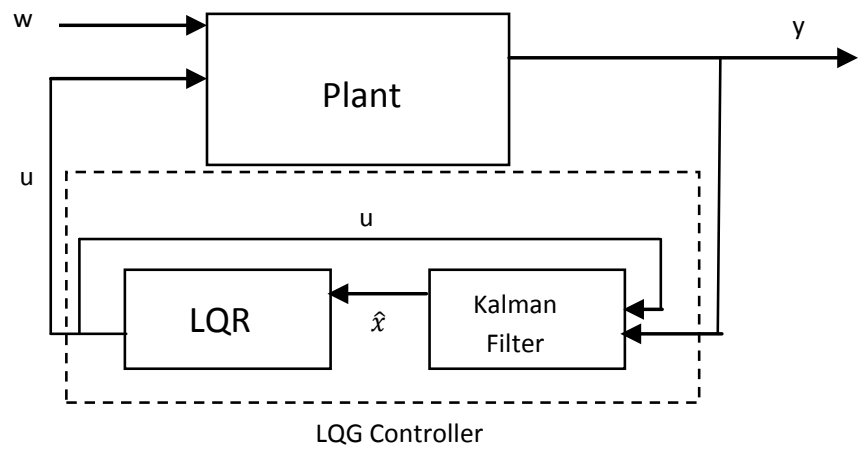

Figure 1. LQG block diagram.

\section{A. Numerical Case}

In order to improve the capability of accurately simulating the nonlinear dynamics of very flexible aircraft, the University of Michigan has recently created the experimental X-HALE aircraft. While the primary purpose for this aircraft is the validation of the simulation codes, it also provides a convenient platform for very flexible aircraft flight control research. The aircraft is a high-aspect ratio wing-boom-tail aircraft. The wing is comprised of eight identical $1 \mathrm{~m}$ sections for a total wingspan of $8 \mathrm{~m}$ with a $0.2 \mathrm{~m}$ chord. The aircraft also has four $0.83 \mathrm{~m}$ horizontal tails, and five motor pods containing not only the $18 \mathrm{~W}$ motors, but also propellers, batteries and processor boards. The two external wing sections are installed with a 10 degree dihedral. ${ }^{3}$ A diagram of the X-HALE aircraft is shown in Fig 2.

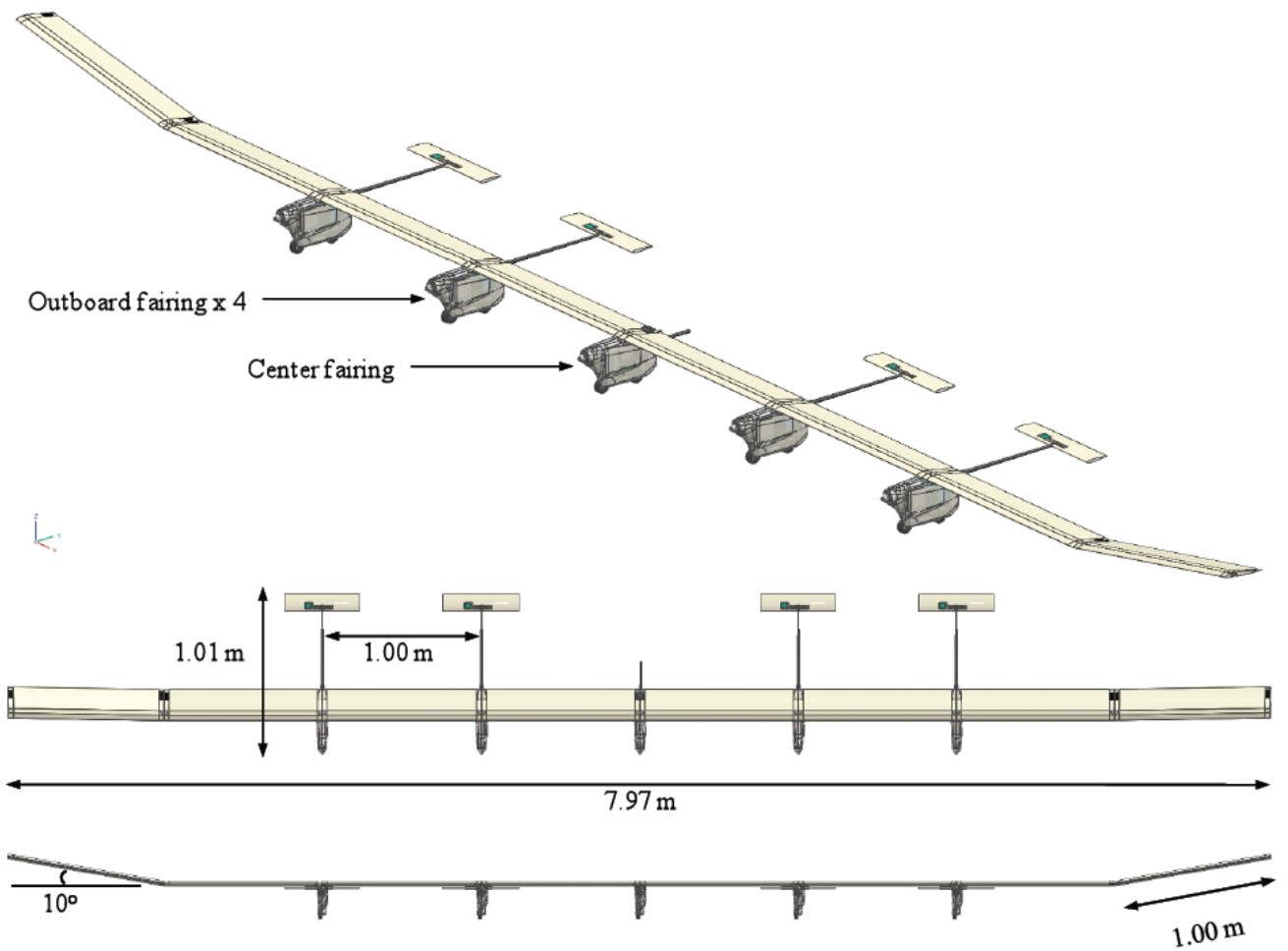

Figure 2. X-HALE isometric, top, and side views. ${ }^{6}$ 
The X-HALE is designed to cruise at speeds ranging between $10 \mathrm{~m} / \mathrm{s}$ and19 m/s. Pitch and roll are controlled using the four horizontal tail surfaces and yaw is controlled using differential thrust. In order to excite the nonlinear wing deformations, a series of scheduled disturbances can be applied to the horizontal tails and to ailerons on the outboard wing sections. The aircraft response can then be measured using on board sensors such as IMUs, strain gauges, and accelerometers. ${ }^{3}$

The XHALE model used in this study is created in UM/NAST using 18 key points (2 per each $1 \mathrm{~m}$ span and one additional at each joint connecting the outboard sections), with each key point containing four strain states (extension, twist curvature, bending about y-axis and bending about $\mathrm{z}$-axis). The 18 wing key points are combined with one key point for each of the five tail booms and two for each tail section. Each key point also contains six unsteady aerodynamic inflow states. The final states are the six body velocities (three translational and three angular), three Euler angles, and three states describing the position of the local frame with respect to the body reference frame. By adding these up, a model with a total of 342 states is obtained. The gust is added to the system as a vertical velocity input applied at 105 locations on the aircraft. As discussed above, given short wingspan of the aircraft, the same gust velocity is applied to all 105 locations.

The linearized model was first manipulated into a form where it has 4 inputs and 8 outputs. The inputs are the left and right side aileron deflections, the flaps deflection (ganged together into a single actuator) and the wind gust input applied across the wingspan of the aircraft. The outputs were the roll, pitch, yaw angles, the pitch rate, the right root curvature, the left root curvature, the right mid-span curvature, and the left mid-span curvature.

\section{B. Model Order Reduction}

As discussed in the preceding section, in order to simplify control design and to speed up simulations, the order of the aircraft model was reduced using the balanced truncation. The first step of this approach is to determine the lower order to be used. The Hankel singular values are plotted in Fig. 3. From examining Fig. 3, the Hankel singular values after $50^{\text {th }}$ are negligible, so the decision was made to use a reduced order system model of order 50.

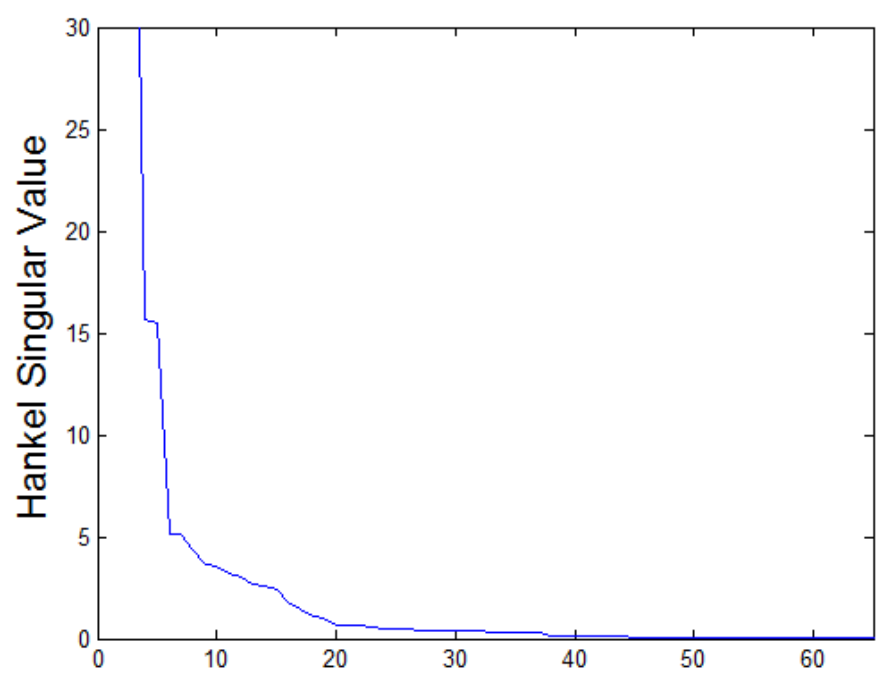

Figure 3. Hankel singular values.

The step and impulse responses of the high order and lower order models were examined in order to verify the accuracy of the reduced order model. A good agreement was found between all input and output pairs. The linear models can also be compared to the full nonlinear model. A step input of magnitude 0.6 deg was applied to the flaps of all three models: nonlinear, full order linear, and reduced order linear. Figure 4 shows a sufficiently good agreement between the nonlinear and linear models. Additionally, the full order linear and reduced order linear models have nearly identical responses. These responses suggest that the control design can proceed using the reduced order linear model. 

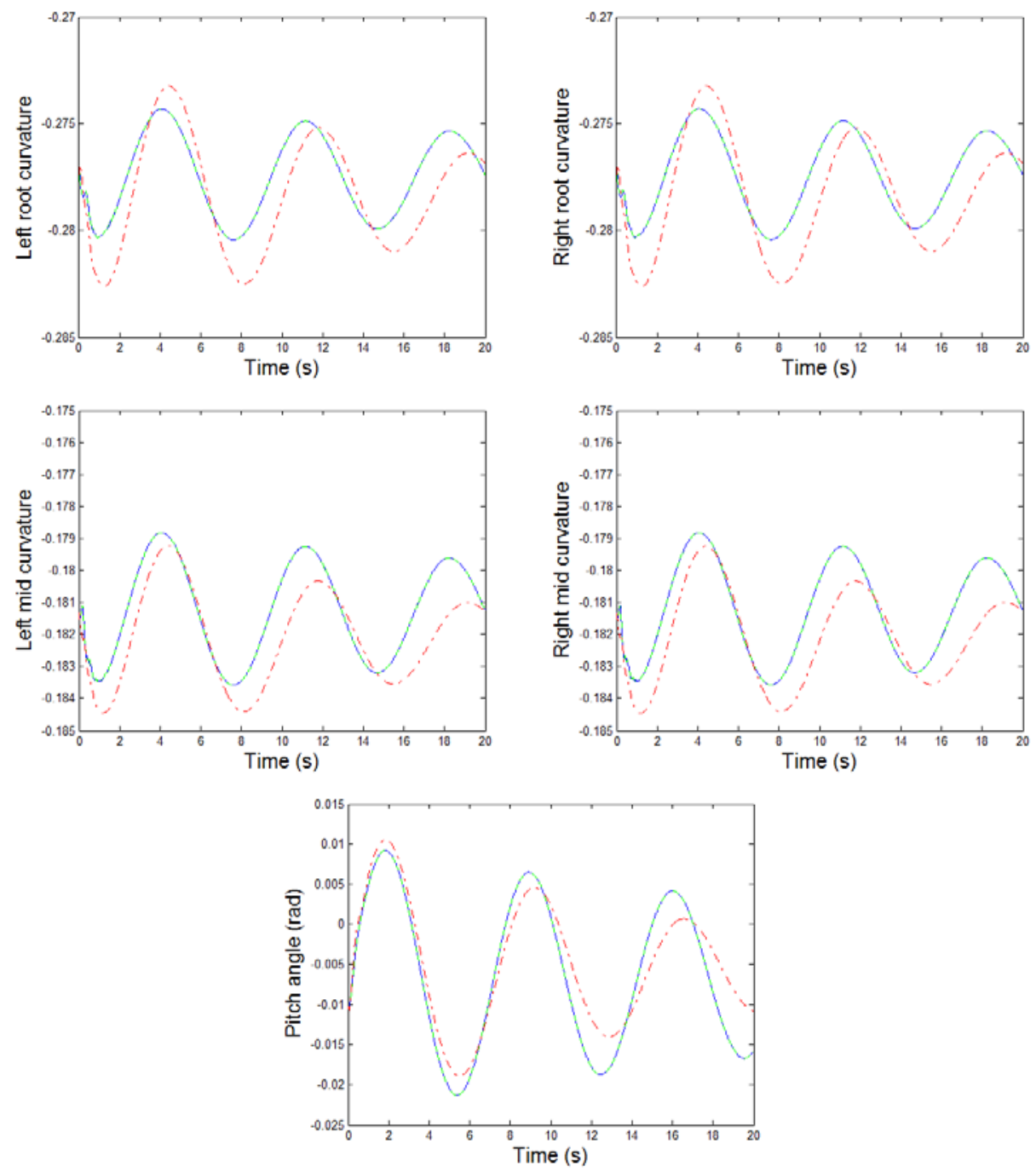

Figure 4. Nonlinear (red, dashed-dotted), full order linear (green,solid) and reduced order linear (blue dashed) loop wing curvature comparison for Dryden1 gust profile: Left Root Curvature (top, left), Right Root Curvature (top, right), Left Mid-span Curvature (middle, left), Right Mid-span Curvature (middle, right), and Pitch Angle (bottom).

\section{Gust Creation}

The gust time histories were created using the Aerospace Blockset of SIMULINK, which is capable of generating gust profiles using both the Dryden and von Karman continuous turbulence models. The wind gust block uses altitude, airspeed and the direction cosine matrix as inputs and it outputs the three dimensional turbulence velocities and angular rates. ${ }^{24}$ For this study only the vertical velocity signal is used. In order to ensure repeatability of the simulations, five different noise seeds were used to create five gust profiles for each model. In this study, the aircraft encounters the gust field one second into the simulation, and the turbulence lasts until 10 seconds, at which point the gust velocity drops to zero. The values used in the creation of the gust profiles were $\mathrm{V}=14 \mathrm{~m} / \mathrm{s}, \mathrm{h}=30 \mathrm{~m}, \mathrm{~L}=2500 \mathrm{ft}(762 \mathrm{~m})$ and the assumption of moderate turbulence. The gust profiles used are shown in Figures 5 and 6 and a comparison between the Dryden and von Karman models is also shown in Fig. 7. 


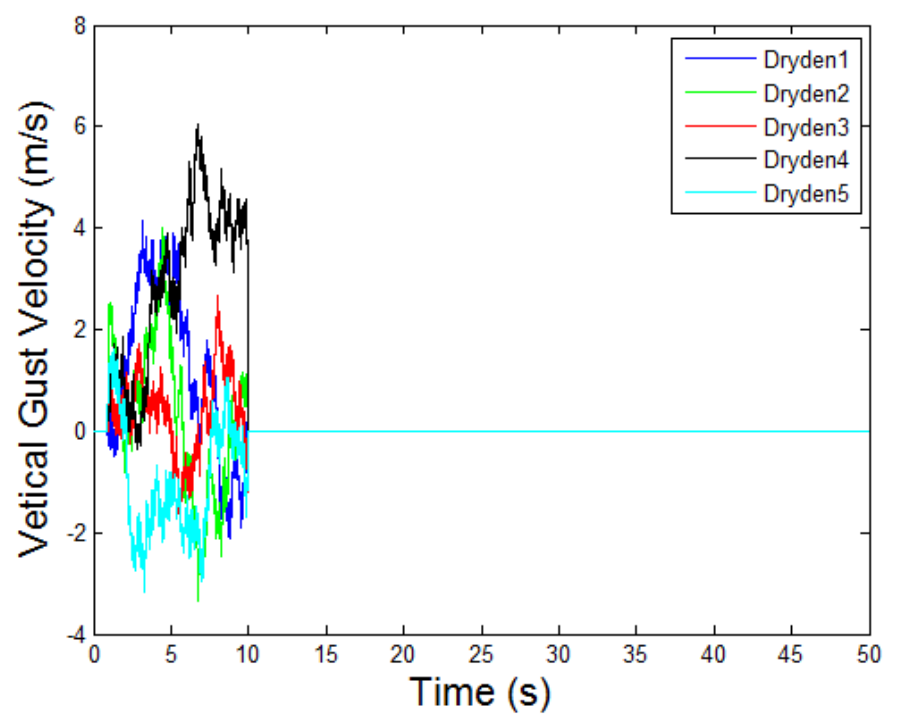

Figure 5. Dryden Gust Profiles.

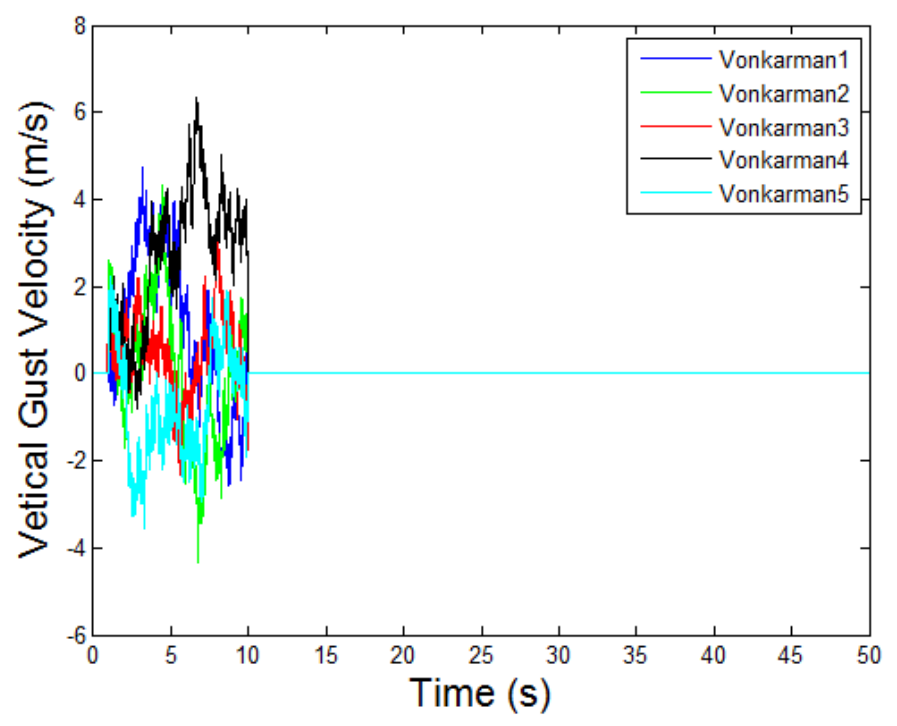

Figure 6. von Karman Gust Profiles. 


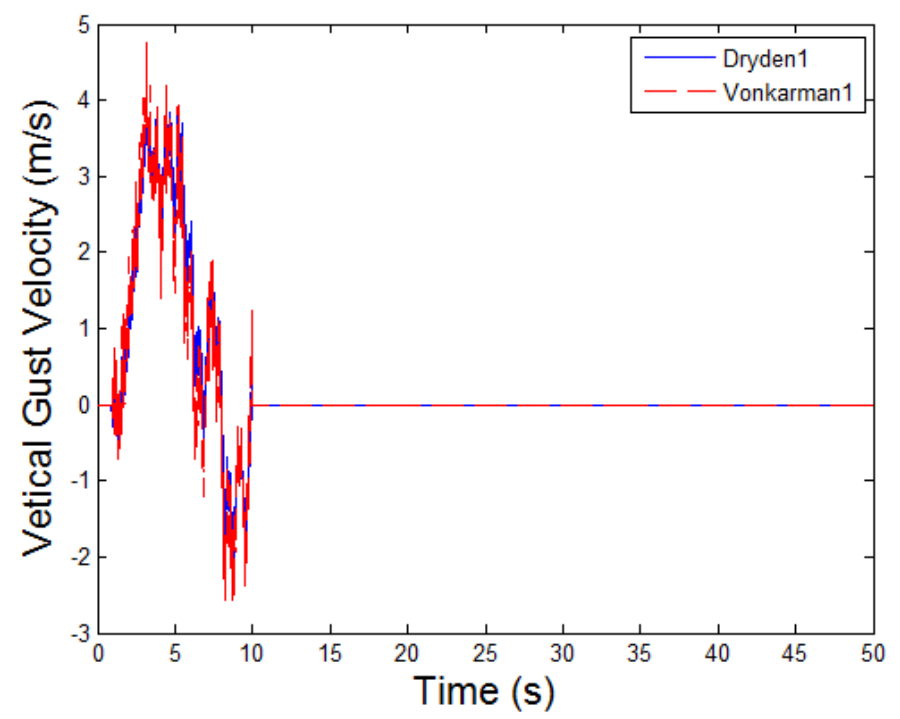

Figure 7. Comparison between Dryden and von Karman Turbulence Models.

\section{Controller Design}

The LQG controller was then designed using the block diagram shown in Fig. 8. The methodology utilized for the control system design was to alleviate the gust loads by controlling the shape of the wing by minimizing the curvature along the span. The wing curvature was measured at four points along the span of the wing. The first two locations are near the center of the span, representing where the wing root would be on a conventional aircraft configuration, and the other two curvatures are measured at the mid-span on both the right and left sides. These signals are included into the model output vector.

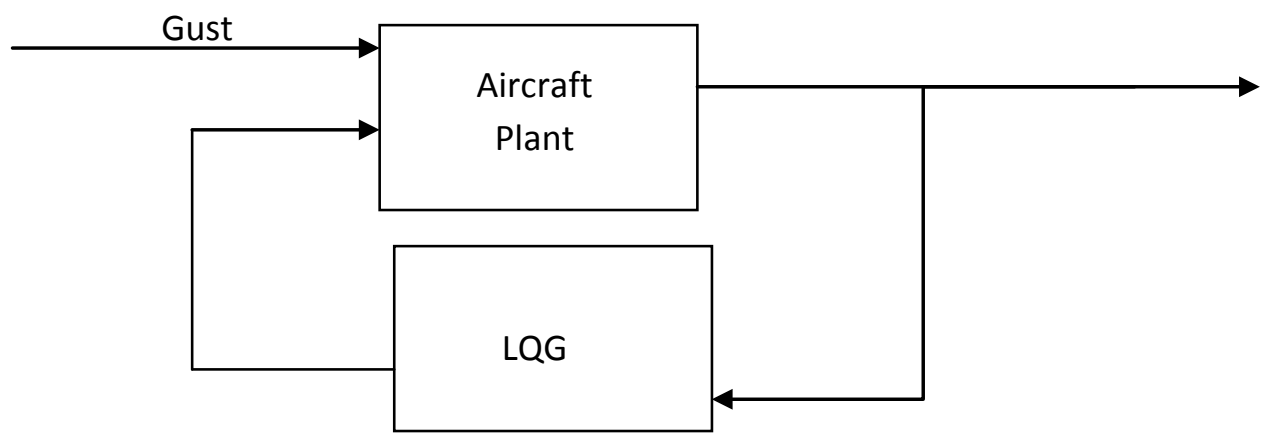

Figure 8. Control System Block Diagram.

The LQG controller uses eight output measurements and produces the three signals (the commands for flaps, the right and left ailerons) to be fed back to the plant. The controller is based on minimizing the following cost function: ${ }^{25}$

$$
J=E\left\{\lim _{T \rightarrow \infty} \frac{1}{T} \int_{0}^{T}\left[\begin{array}{ll}
x^{\prime} & u^{\prime}
\end{array}\right] Q X U\left[\begin{array}{l}
x \\
u
\end{array}\right] d t\right\}
$$

where $\mathrm{E}\{$.$\} is the expectation, x$ is the state vector, $u$ is the control vector, $x^{\prime}$ denotes the transpose of $\mathrm{x}$ and $Q X U$ is the aggregated state and control weighting matrix. This weighting matrix is used as a design parameter to impart the system the desired characteristics. It was designed as a block diagonal matrix, with two blocks designed to penalize the states and controls, respectively. 


$$
Q X U=\left[\begin{array}{cc}
M & 0 \\
0 & R
\end{array}\right]
$$

where $\mathrm{M}$ is the matrix penalizing the states and $\mathrm{R}$ is the matrix penalizing the controls. The matrices $\mathrm{M}$ and $\mathrm{R}$ were chosen as diagonal with elements tuned in simulations for best system performance. In the Kalman Filter design, the measurement noise and the gust noise were assumed to be uncorrelated. To ensure that the control system is capable of handling a broad range of disturbances, LQG design was based on a plant model not augmented with the gust filter.

\section{E. Gust Studies}

The controller was then used to run multiple simulations on the reduced order, linear system, using the five Dryden and five von Karman gust profiles described above. It was shown to reduce the maximum curvature values by an average of $47 \%$ and the RMS curvatures were reduced by an average of $83.7 \%$. Example plots are shown in Fig. 9 and the results for all the simulations are summarized in Tables 1 and 2. All of the simulations were done at the single operating point of $\mathrm{V}=14 \mathrm{~m} / \mathrm{s}$ and an altitude of $30 \mathrm{~m}$. This is a typical operating point for the $8 \mathrm{~m}$ XHALE model used. The approach can be easily extended to the entire flight envelope by employing gain scheduling. In gain scheduling, the optimal controller gains are calculated a priori at every flight condition within the flight envelope and then stored onboard the aircraft as a look-up table.
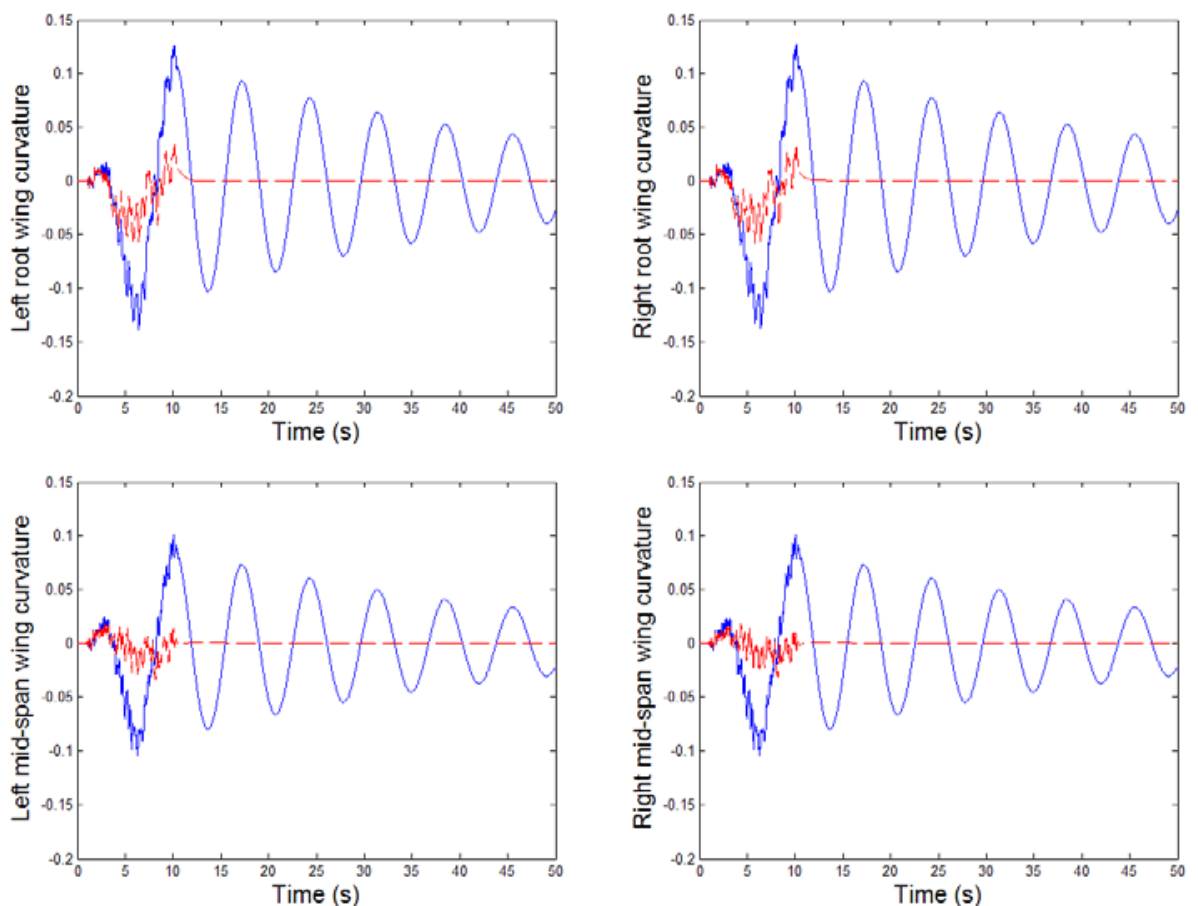

Figure 9. Open (blue) and closed (red dashed) loop wing curvature comparison for Dryden1 gust profile: Left Root Curvature (top, left), Right Root Curvature (top, right), Left Mid-span Curvature (bottom, left), Right Midspan Curvature (bottom, right).

Table 1. Percent Reduction in Peak Wing Curvatures for Dryden Models.

\begin{tabular}{|l|l|l|l|l|l|}
\hline & Dryden 1 & Dryden 2 & Dryden 3 & Dryden 4 & Dryden 5 \\
\hline Right Root Curvature & 57.9 & 60.7 & 51.9 & 22.9 & 35.8 \\
\hline Left Root Curvature & 59.4 & 60.1 & 47.5 & 23.7 & 36.5 \\
\hline Right Mid-span Curvature & 70.5 & 52.7 & 55.3 & 30.2 & 55.3 \\
\hline Left Mid-span Curvature & 67.6 & 51.9 & 51.9 & 27.9 & 48.8 \\
\hline
\end{tabular}


Table 2. Percent Reduction in Peak Wing Curvatures for Dryden Models.

\begin{tabular}{|l|l|l|l|l|l|}
\hline & von Karman 1 & von Karman 2 & von Karman 3 & von Karman 4 & von Karman 5 \\
\hline Right Root Curvature & 53.8 & 55.9 & 48.6 & 23.0 & 32.9 \\
\hline Left Root Curvature & 55.6 & 55.1 & 44.9 & 24.9 & 33.4 \\
\hline Right Mid-span Curvature & 68.9 & 59.8 & 49.8 & 24.5 & 49.0 \\
\hline Left Mid-span Curvature & 65.3 & 58.3 & 47.0 & 21.1 & 47.4 \\
\hline
\end{tabular}

The control deflections are shown in Fig. 10. Note that the flap deflections are relatively small; this is reasonable since the flaps are constrained to move together and they have little effect on the curvature of the wing. Also note that the aileron deflections are essentially symmetric, which is expected given the symmetric spanwise nature of the gust profile used. The maximum absolute value of the aileron deflections was found to be 12 degrees for a moderate turbulence gust input with a maximum value of approximately $6 \mathrm{~m} / \mathrm{s}$. The high frequency content of the control signals is most likely due to the high frequency nature of the gust input, which has a sampling time of $0.001 \mathrm{~s}$. The closed-loop simulations assumed fast actuator dynamics. The simulations were also repeated with first order actuator dynamics augmented; the controller has shown stable response with slight $(\sim 2 \%)$ degradation of the curvature excursion performance.
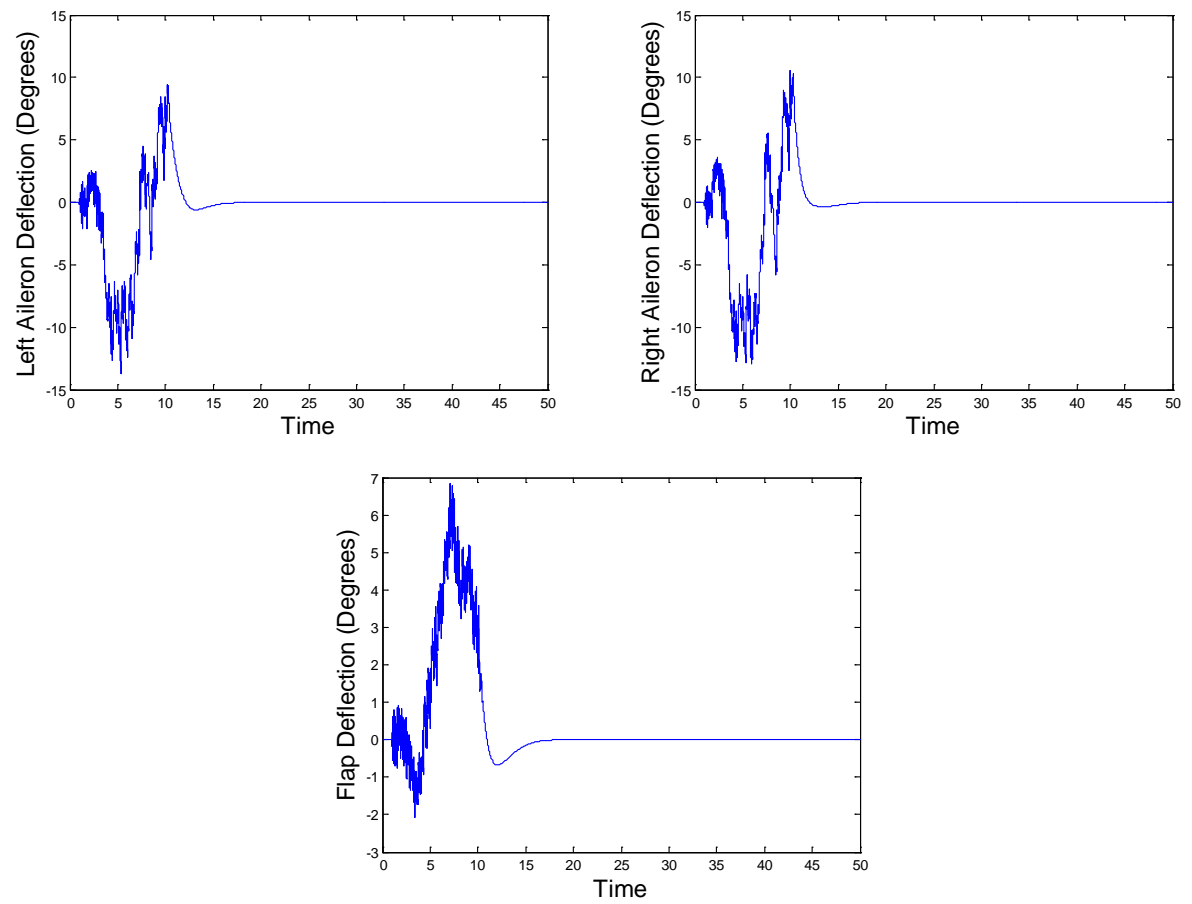

Figure 10. Control surface deflections: Left aileron (top, left), Right aileron (top, right), Flaps (bottom)

Next, an integrator on pitch angle was added to the system model so that pitch angle command tracking in the presence of the gust disturbance can be demonstrated. Additionally, the M matrix was modified. The details on the formulation of the tracking controller are included in the appendix. The LQG controller was then formed in the same fashion as above. In order to show the pitch angle tracking controller functions properly, the gust used in this simulation occurred throughout the entire simulation time, versus only on from 1 to 10 seconds as was used above. Results for this simulation are shown below in Figs. 11 and 12. In the Figs, the open loop response is the system response to the gust input only. 


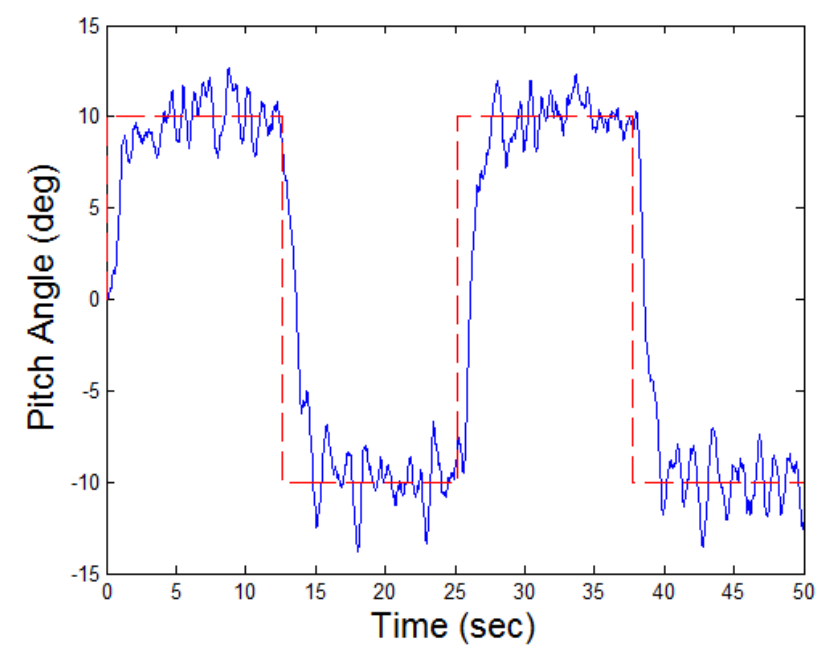

Figure 11. Pitch angle command tracking simulation results.
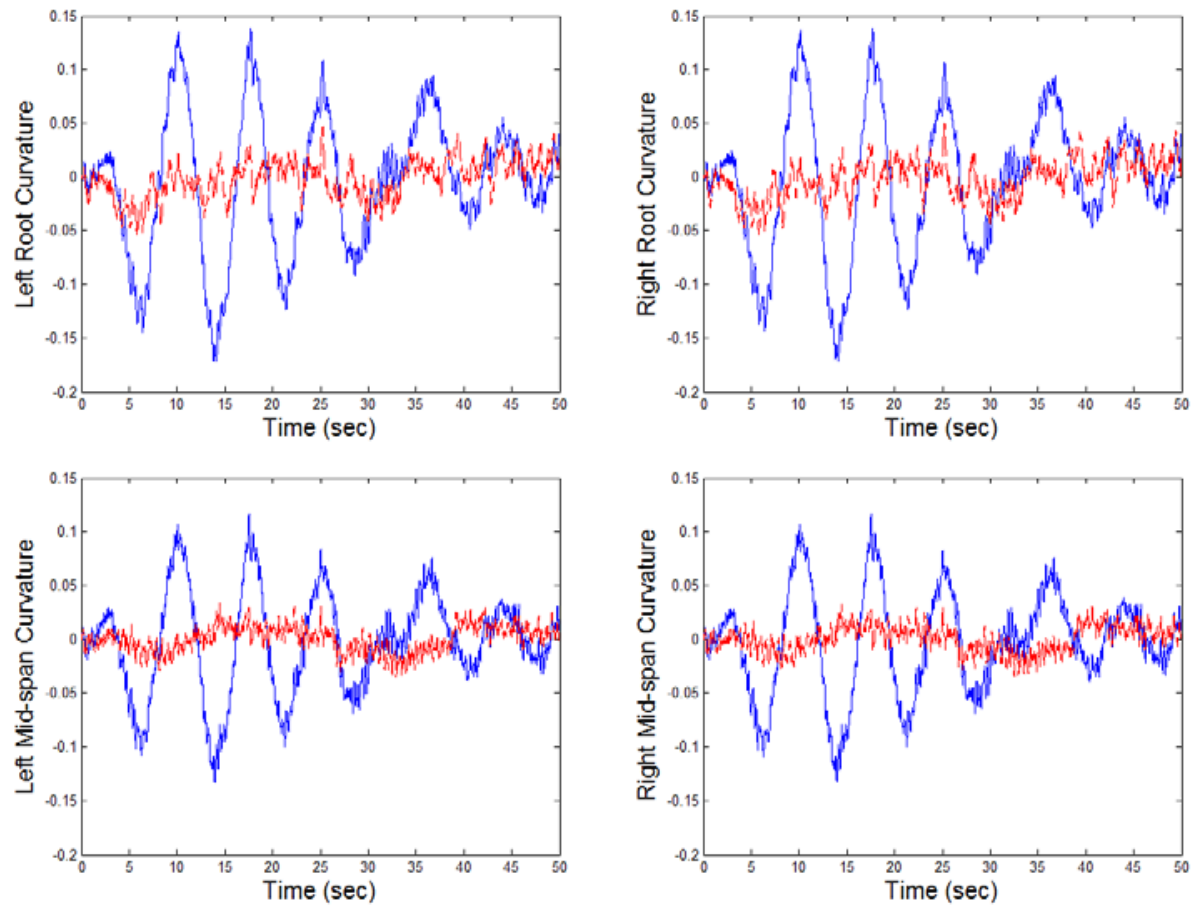

Figure 12. Open (blue) and closed (red dashed) loop wing curvature comparison for pitch tracking simulation: Left Root Curvature (top, left), Right Root Curvature (top, right), Left Mid-span Curvature (bottom, left), Right Mid-span Curvature (bottom, right).

The controller matches the pitch command very well, despite the influence of the gust throughout the entire simulation. Additionally, all four wing curvatures are substantially reduced throughout the simulation. Next the control surface deflections were examined. They are shown in Fig. 13. 

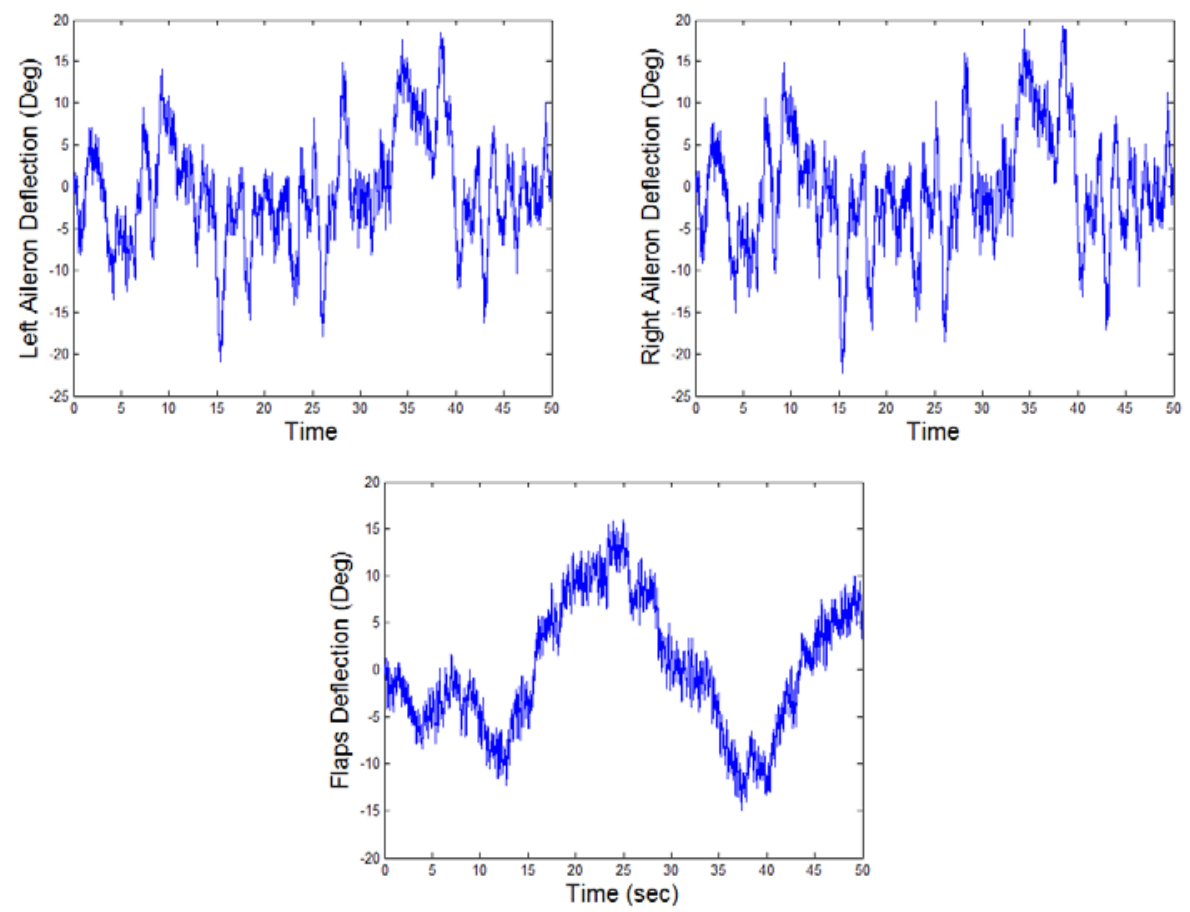

Figure 13. Control surface deflections during pitch tracking: Left aileron (top, left), Right aileron (top, right), Flaps (bottom).

The two simulations were then compared to see if the integrator or new control weighting matrix had any effect on the reduction in wing curvatures. In order to compare the two simulations, the pitch command was set to zero and the gust input from one to ten seconds was used. The simulation was then run with these conditions and the results are shown in Fig. 14.
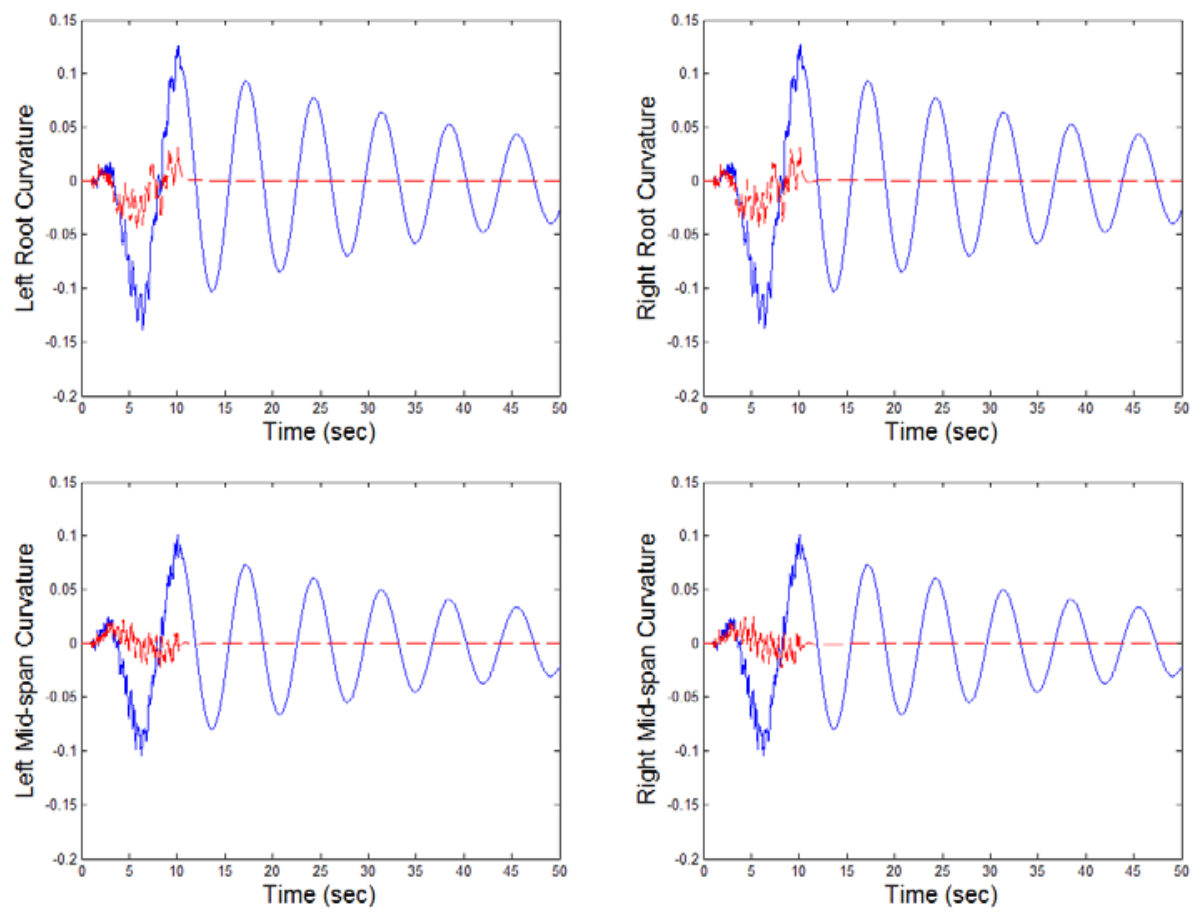

Figure 14. Open (blue) and closed (red dashed) loop wing curvature comparison for pitch tracking simulation: Left Root Curvature (top, left), Right Root Curvature (top, right), Left Mid-span Curvature (bottom, left), Right Mid-span Curvature (bottom, right). 
The controller was shown to provide a better reduction in the root curvatures than the first controller by reducing the maximum curvature by an average of $56 \%$ as well as a reduction in RMS curvatures by an average of $83.2 \%$. The second controller also provided much higher reductions in the mid-span curvatures, while using similar aileron deflections to the first controller. The control surface deflections are shown in Fig. 15.
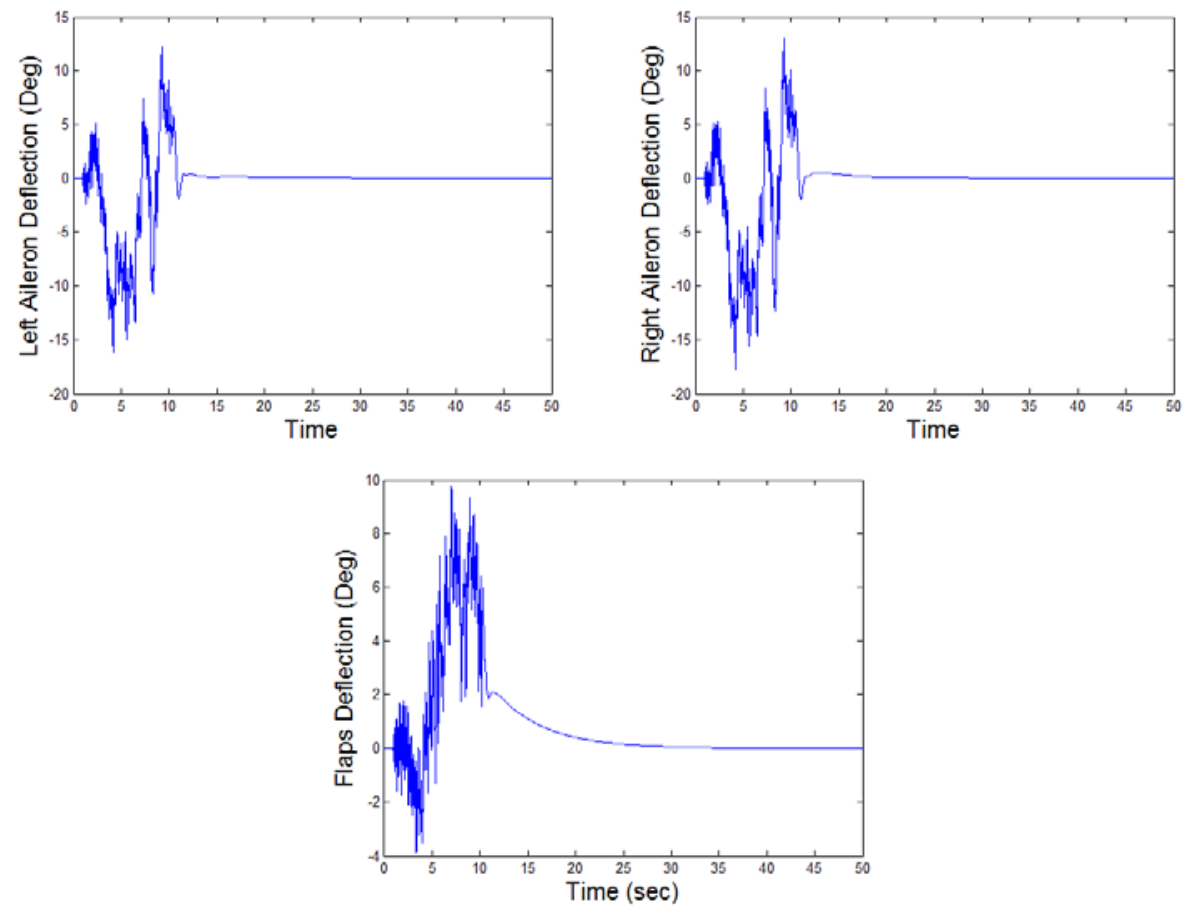

Figure 15. Control surface deflections during pitch tracking: Left aileron (top, left), Right aileron (top, right), Flaps (bottom).

To strictly enforce limits on structural deflections during aircraft maneuvering, the reference governor approach ${ }^{26}$ can be used. Here we demonstrate its application to pitch angle command following during the time periods when the aircraft is not experiencing the gust disturbance. The reference governor is a first order linear filter with an adjustable bandwidth parameter,

$$
v(t+1)=v(t)+\kappa(t)(r(t)-v(t))
$$

where $r(t)$ denotes the pitch angle command, $v(t)$ denotes the filtered pitch angle command which is passed on to the LQG controller and $0 \leq \kappa(t) \leq 1$. The parameter $\kappa(t)$ is maximized at each instant of time, subject to the constraint that the predicted aircraft response, based on the linear model and state estimate from the Kalman filter as an initial condition, does not violate the imposed constraints on the structural deflections. Figures 16-18 illustrate the reference governing of a sequence of $+/-8$ deg steps in the commanded pitch angle. The hard limits imposed on the four curvatures of 0.01 are strictly enforced by the reference governor which slows down the pitch command as needed to avoid constraint violation. The extension of the reference governor to simultaneous pitching and gust disturbance rejection will be pursued in separate publications. This extension benefits from more conservative constraint tightening to account for the presence of the gust and from the on-line prediction of the gust induced forces and moments on the aircraft. 


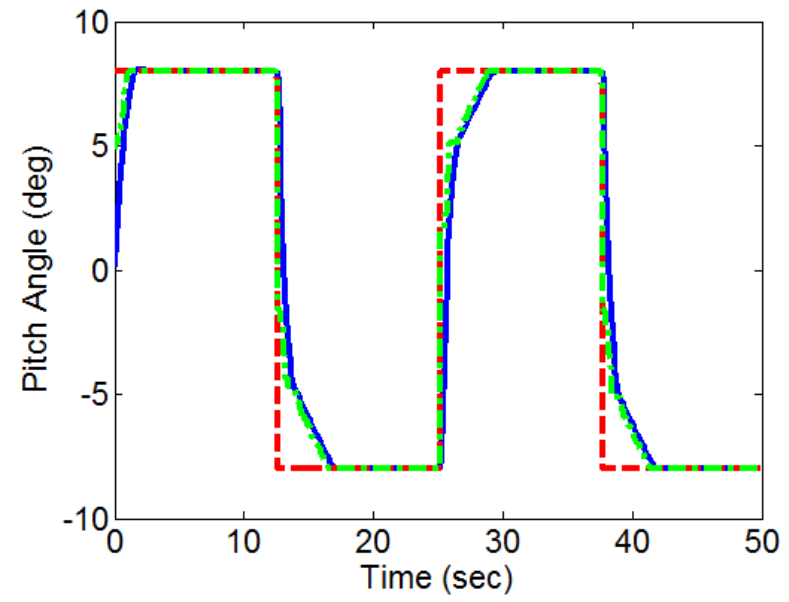

Figure 16. Commanded (dashed), filtered by reference governor (dash-dot) and actual (solid) pitch angle time histories for the zero gust pitch angle command tracking simulation with the reference governor.
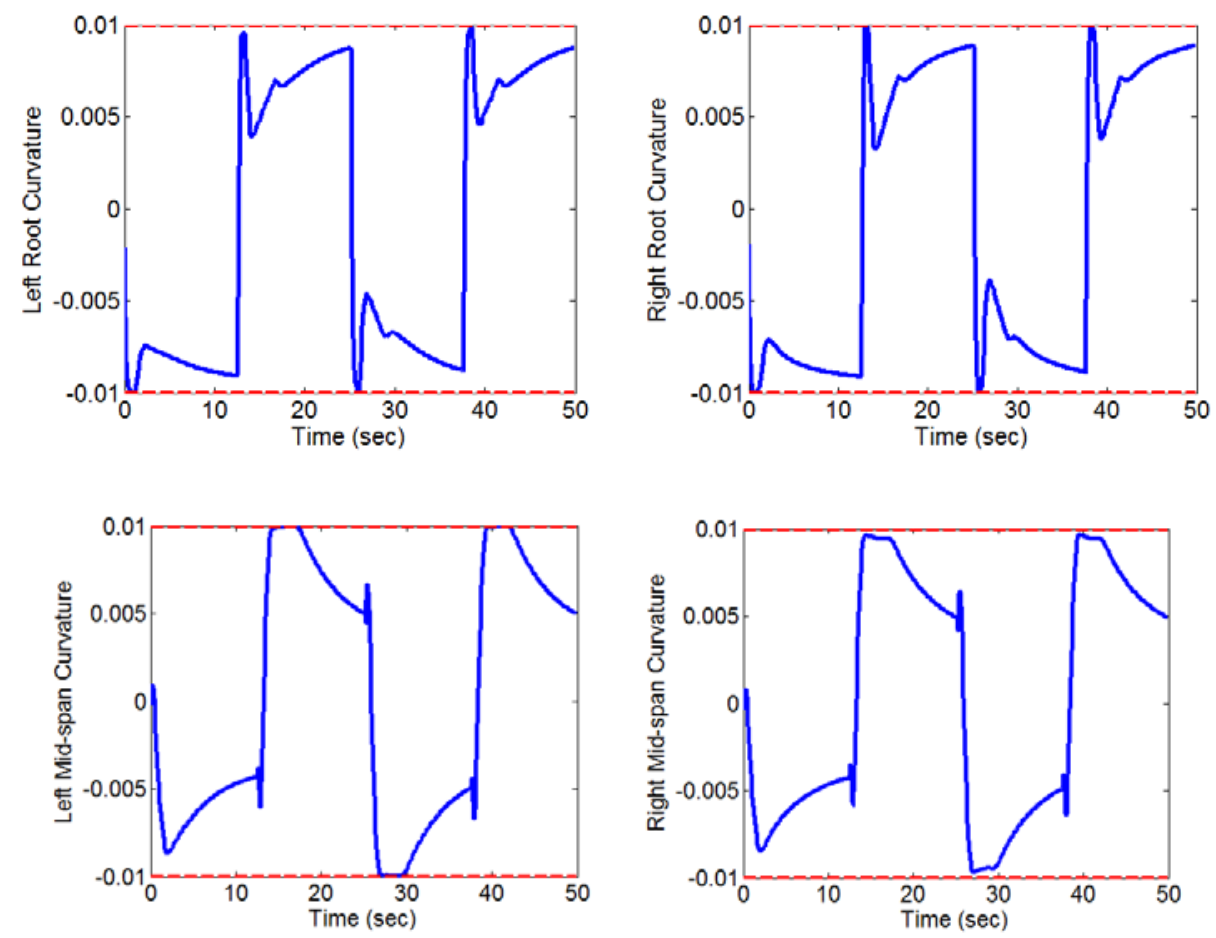

Figure 17. Structural deflections for the zero gust pitch angle command simulation with the reference governor: Left Root Curvature (top, left), Right Root Curvature (top, right), Left Mid-span Curvature (bottom, left), Right Mid-span Curvature (bottom, right). The constraints are represented by the dashed lines. 

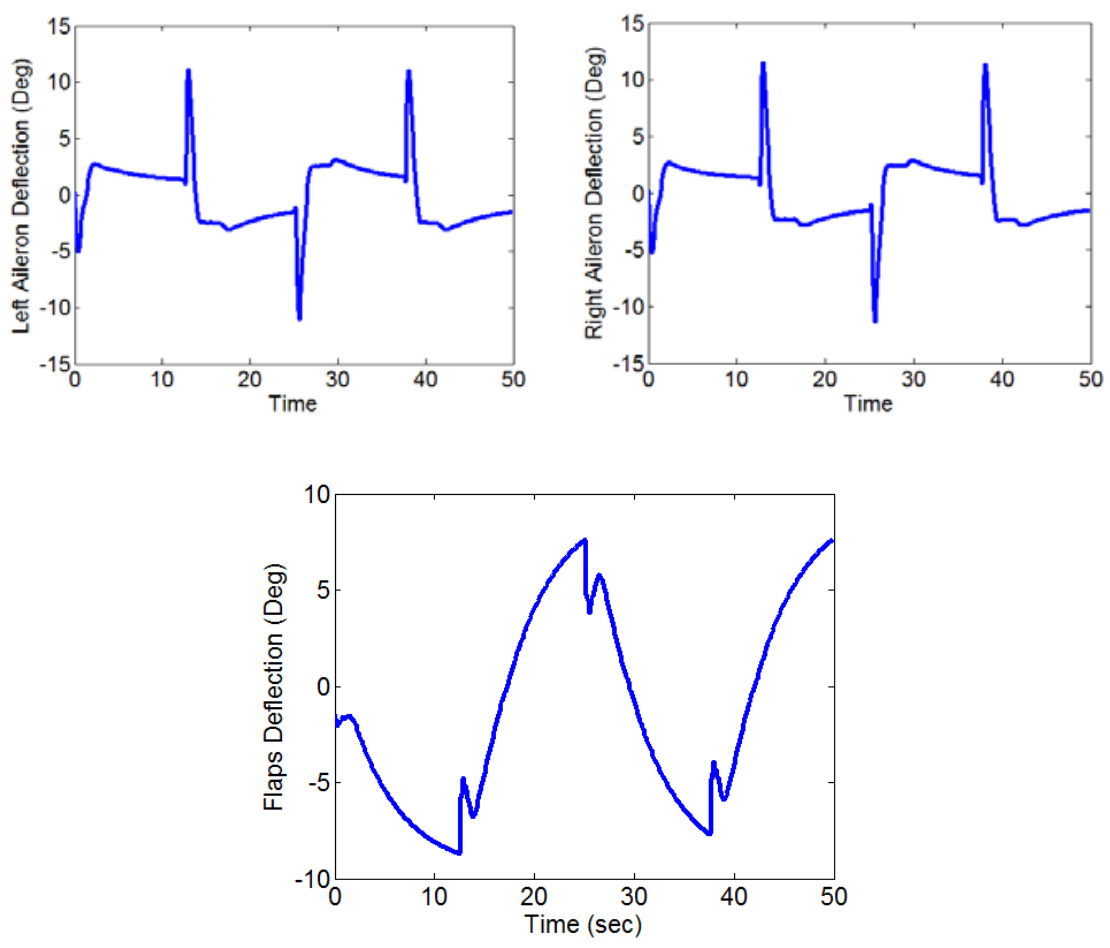

Figure 18. Control time histories for the zero gust pitch angle command following simulation with the reference governor: Left aileron deflection (top, left), Right aileron deflection (top, right), flaps deflection (bottom).

\section{Conclusion}

A method for reducing the effect of wind gust loads on very flexible aircraft by controlling their shape and minimizing their wing curvature was presented. Several different gust time histories were created using the Dryden and von Karman stochastic gust models. An LQG controller was designed to reject the gust disturbance. The controller was shown to reduce the linear model peak wing curvatures by an average of $47 \%$ and RMS curvatures by an average of $83.7 \%$. An integrator was then added to create a pitch angle command tracking system. The controller was shown to track a command in the linear model very well, while at the same time minimizing the wing curvatures. The pitch command tracking controller was then applied to the system with a command of zero degree. This controller was shown to better results than the earlier controller with a 56\% reduction in peak curvature values. Finally, it was demonstrated a reference governor for modifying the pitch angle reference was successful in limiting the curvatures of the linear model below a specified limit.

\section{Appendix}

The augmented plant model for the tracking controller is given as:

$$
\begin{array}{cc}
A=\left[\begin{array}{cc}
A_{\text {plant }} & 0 \\
-C_{\text {plant }(5,:)} & 0
\end{array}\right] & B=\left[\begin{array}{c}
B_{\text {plant }} \\
-D_{\text {plant }(5,:)}
\end{array}\right] \\
C=\left[\begin{array}{cc}
C_{-} \text {plant } & 0 \\
0 & 1
\end{array}\right] & D=\left[\begin{array}{c}
D \_ \text {plant } \\
0
\end{array}\right]
\end{array}
$$

where the *_plant matrices are the original system matrices used in the above simulations, and the $5^{\text {th }}$ channel used in the equations corresponds to the pitch angle output. Additionally the M matrix used in the construction of the state and control weighting matrix was also modified to directly penalize the curvature outputs as well as the yaw and roll angles to a lesser degree. The M matrix now has the form: 


$$
M=\rho I_{50} C_{1}^{T} C_{1}+\frac{\rho}{1000} I_{50} C_{2}^{T} C_{2}+\rho I_{50}+m_{51}
$$

where $\rho$ is the design parameter used above and set to $1 \mathrm{e} 6$ for this study, $I_{50}$ is the $50 \mathrm{x} 50$ identity matrix, $C_{1}$ contains the rows of the $C$ matrix corresponding to the 4 wing curvatures being used, $C_{2}$ contains the rows of the $C$ matrix corresponding to the yaw and roll angles, and $\mathrm{m}_{51}$ is a $51 \mathrm{x} 51$ matrix containing all zeros except for the $(51,51)$ element corresponding to the integrator state, which was set to $10^{4}$.

\section{Acknowledgements}

The authors are very grateful to Dr. Weihua Su without whose expert assistance with X-HALE aircraft modeling and linearization, as well as his extensive knowledge of the UM/NAST software package, this work would not have been possible.

\section{References}

${ }^{1}$ Patil, M.J., Hodges, D.H., and Cesnik, C. E. S., "Nonlinear Aeroelasticity and Flight Dynamics of High Altitude Long Endurance Aircraft,” AIAA 40 ${ }^{\text {th }}$ Structures, Structural Dynamics and Materials Conference, St. Louis, Missouri, April 12-15 1999, AIAA-99-1470.

2Tilmann, C.P., Flick, P.M., Martin, C. A., and Love, M.H., "High-Altitude Long Endurance Technologies for SensorCraft,” RTO AVT Symposium on "Novel Vehicle Concepts and Emerging Vehicle Technologies", Brussels, Belgium, April 7-10 2003, MP-104-P-26-1.

${ }^{3}$ Cesnik, C.E.S., Senatore, P.J., Su, W., Atkins, E.M., Shearer, C.M., and Pitcher, N.A., "X-HALE: A Very Flexible UAV for Nonlinear Elastic Tests,” 51stAIAA/ASME/ASCE/AHS/ASC Structures, Structural Dynamics, and Materials Conference, April 12-15 2010, Orlando, FL.

${ }^{4}$ Patil, M. J., Hodges, D. H., and Cesnik, C. E. S., "Nonlinear Aeroelasticity and Flight Dynamics of High-Altitude Long Endurance Aircraft,” Journal of Aircraft. Vol. 38, No. 1 Jan. - Feb. 2001.

${ }^{5} \mathrm{Su}$, W., and Cesnk, C. E. S., "Dynamic Response of Highly Flexible Flying Wings,” AIAA Journal, Vol. 49, No. 2, February 2011, pp.324-339.

${ }^{6}$ Palacios, R., and Cesnik, C.E.S., "Strucural Models for Flight Dynamic Analysis of Very Flexible Aircraft," $50^{\text {th }}$ AIAA/ASME/ASCE/AHS/ASC Structures, Structural Dynamics, and Materials Conference, 4-7 May 2009, Palm Springs, CA.

${ }^{7}$ Palacios, R., Murua, J., and Cook, R., "Structural and Aerodynamic Models in Nonlinear Flight Dynamics of Very Flexible Aircraft,” AIAA Journal, Vol 48, No 11, November 2010.

'Zhou, Z. and Ren, G.,"Multibody Dynamic Approach of Flight Dynamics and Nonlinear Aeroelasticy of Flexible Aircraft," AIAA Journal, Vol 49, No 1, January 2011.

${ }^{9}$ Noll, T.E., Brown, J.M., Perez-Davis, M.E., Ishmael, S.D., Tiffany, G.C., and Gaier, M., "Investigation of the Helios Prototype Aircraft Mishap,” January 2004.

${ }^{10}$ McLean, D., “Gust Load Alleviation Control Sytems for Aircraft,” Proceedings of IEEE, Vol. 125, No. 7, July 1978.

${ }^{11}$ Botez, R.M., Boustani, I., and Vayani, N., "Optimal Control Laws for Gust Load Alleviation,” Proceedings of the 46th Annual CASI Conference, 3-5 May, 1999, Montreal, Quebec, Canada.

${ }^{12}$ Aouf, N., Boulet, B., and Botez, R., "H2 and H-infinity Optimal Gust Load Alleviation for a Flexible Aircraft,” ACC00AIAA1015.

${ }^{13}$ Rui, W., Xiaoping, Z., Zhou, Z., “Design Gust Alleviation Controller for Highly Flexible Solar UAV,” 2011 Third International Conference on Measuring Technology and Mechatronics Automation.

${ }^{14}$ anon, Federal Aviation Regulation 23, Federal Aviation Administration, United States of America.

${ }^{15}$ Hoblit, F.M., Gust Loads on Aircraft: Concepts and Applications, AIAA Education Series, Washington, D.C., 1988.

${ }^{16}$ Kabamba, P.T., AEROSP 584 class notes, The University of Michigan, Ann Arbor, MI, 2010.

${ }^{17}$ Dietrich, F., Response of an Airplane to Random Atmospheric Disturbances, NACA TN3910, April 1957.

${ }^{18} \mathrm{Su}, \mathrm{W} .$, “Coupled Nonlinear Aeroelasticity and Flight Dynamics of Fully Flexible Aircraft.” Ph.D. Dissertation, University of Michigan, Ann Arbor, MI, 2008.

${ }^{19}$ Peters, D.A. and Johnson, M.J., "Finite State Airloads for Deformable Airfoils on Fixed and Rotating Wings,” Proceedings of Symposium on Aeroelasticity and Fluid/Structure Interaction/Proceedings of the Winter Annual Meeting, Fairfield, NJ, 1994.

${ }^{20}$ Shearer, C.M., and Cesnik, C.E.S., “Nonlinear Flight Dynamics of Very Flexible Aircraft,” Journal of Aircraft, Vol.44, No.5, 2007, pp. 1528-1545.

${ }^{21}$ Cesnik, C.E.S, and Su, W., "Nonlinear Aeroelastic Modeling and Analysis of Fully Flexible Aircraft," 46 ${ }^{\text {th }}$ AIAA/ASME/ASCE/AHS/ASC Structures, Structural Dynamics and Material Conference, 18-21 April 2005, Austin, TX.

${ }^{22}$ Skogestag, S. and Postlethwaite,I., Multivariable Feedback Control Analysis and Design, John Wiley and Sons, 2005. 
${ }^{23}$ Maddi, A., Guessoum, A., and Berkani, D., "Using Linear Quadratic Gaussian Optimal Control for Lateral Motion of Aircraft,” World Academy of Science, Engineering, and Technology, 492009.

${ }^{24}$ Gage, S. "Creating a Unified Graphical Wind Turbulence Model from Multiple Specifications.” AIAA Modeling and Simulation Technologies Conference and Exhibit, 11-14 August 2003, Austin, TX.

${ }^{25}$ MATLAB LQG help file, The Mathworks inc., 2010.

${ }^{26}$ Gilbert, E., and Kolmanovsky, I.V., "Fast Reference Governors for Systems with State and Control Constraints and Disturbance Inputs,” International Journal of Robust and Nonlinear Control, Vol 9, no 15, pp 1117-1141, December 1999. 